\title{
Chemical profiling of volatile organic compounds from shoe odour for personal identification
}

\author{
Muhammad Hafizuddin Mohd Kamal' ${ }^{1}$, Yusmazura Zakaria², Muhammad Lokman Md Isa ${ }^{3}$ and \\ Nik Fakhuruddin Nik Hassan ${ }^{1 *}$ (D)
}

\begin{abstract}
Background: Body odour of an individual has a unique composition due to the combined influences of genetic, dietary, and environmental factors. This exploratory study was conducted to investigate the feasibility of obtaining unique chemical signatures of individuals from the shoe odour as a human chemical fingerprint for forensic identification.

Methods: Five adult males and five adult females participated in this study and provided with two pairs of new canvas sports shoes. The participants were asked to do strenuous activities while wearing the shoes for 2 weeks. Two different extraction methods: swabbing technique, followed with direct extraction using different solvents, and air passive sampling technique, were compared for the effectiveness to extract the volatile organic compounds (VOCs) from the shoes. The variations of VOCs were investigated using gas chromatography coupled with flame ionisation detector (GC-FID), and the resultant chromatogram profiles collected from the shoe odour were further studied for individual identification purposes. In addition, principal component-discriminant analyses (PCA-DA) were then carried out on the GC dataset.

Results: This study demonstrated that air passive sampling technique using methanol as the extraction solvent was effective for the detection of shoe odour. PCA-DA had successfully distinguished GC profile patterns and discriminated the shoe odour samples accordingly to their owners. The accuracy of DA for classification was $100 \%$, with all samples were classified correctly to their groups.

Conclusion: The chemical compounds of shoe odour have the potential to be utilised to aid the forensic investigation by identifying and narrowing down the possible suspect if shoes were recovered as evidence at the crime scene.
\end{abstract}

Keywords: Body odour, Shoe odour, VOCs, Gas chromatography, Principal component analysis, Discriminant analysis

\section{Background}

Human body odour is a mixture of volatile organic compounds (VOCs) that is produced by human skin through sweat secretions(Rajan et al., 2013). Human body odour profiling can be utilised as biometric in personal identification and becomes a highly sought application for criminal investigation and determination of disease (Curran et al., 2005).

\footnotetext{
*Correspondence: nikf@usm.my

${ }^{1}$ Forensic Science Programme, School of Health Sciences, Universiti Sains Malaysia, Kubang Kerian, Kelantan, Malaysia

Full list of author information is available at the end of the article
}

There are three types of odour, namely primary, secondary, and tertiary odours. The primary odour is derived from the genetic makeup of the person (Rajan, 2015). This type of odour is strongly helpful in the identification or uniqueness of the individuals due to the genetic condition that is unchanged for the whole life (Li, 2014). The secondary odour results from the changes in dietary and environment on an individual (Jeltema \& Southwick, 1986). The tertiary odour is influenced by external sources such as skincare and cosmetic product (Curran et al., 2007).

\section{Springer Open}

(๑) The Author(s). 2020 Open Access This article is licensed under a Creative Commons Attribution 4.0 International License, which permits use, sharing, adaptation, distribution and reproduction in any medium or format, as long as you give appropriate credit to the original author(s) and the source, provide a link to the Creative Commons licence, and indicate if changes were made. The images or other third party material in this article are included in the article's Creative Commons licence, unless indicated otherwise in a credit line to the material. If material is not included in the article's Creative Commons licence and your intended use is not permitted by statutory regulation or exceeds the permitted use, you will need to obtain permission directly from the copyright holder. To view a copy of this licence, visit http://creativecommons.org/licenses/by/4.0/. 
The characteristic of human body odour is known as "body odour signature", and it is of paramount importance in providing information about the odour producer (Brown et al., 2013). It provides a variety of circumstances in the investigation process of criminal cases (Hunt, 1999). Human body odour is different between persons and has a genetically characteristic which is unique. The odour could be used to determine the individuality, gender, reproductive status, age, health, diet, smoking habits, hygiene, presence of abnormal substances, microorganism activities and others (Jacob et al., 2002; Sorokowska et al., 2015; Marshall et al., 1988; Ara et al., 2006; Havlicek \& Lenochova, 2008; Gallagher et al., 2008; Wallace, 1977; Jha \& Hayashi, 2017; Shirasu \& Touhara, 2011).

Combination of a various compound in the different ratio for people make it differs from one person to another person (Curran \& Furton, 2005). The odour of individuals does not only differ amongst people who are genetically different but also to their parents and twin siblings (Kalmus, 1955). The study was carried out on the scent collected from different parts of the body, such as hair, skin, breath as well as foot and the results demonstrated a highly significant discrimination power which more than $98.9 \%$ of the individuals were distinguishable.

Body odour has an association with the ageing of a person. Unsaturated C9 aldehyde I-2-nonenal is the compound in odour associated with ageing (Haze et al., 2001). As the age increases, the amount of this compound found on the skin has also increased. Males were reported to be more odorous and produce an unpleasant scent than females (Sergeant, 2010). The presence of Corynebacterium bacteria and larger apocrine glands found in males have associated with more intense and pungent malodour of the male body (Pickett, 2017; Rennie et al., 1991).

Different regions of the body have different VOCs profile, thus producing different odours. Even though the compound is different between regions of the body, they share the same primary odour compound. Essentially, volatile organic compounds extracted from the skin can be divided into seven groups: acids, alcohols, aldehydes, hydrocarbon, ester, ketone, and nitrogen-containing compound (Gorea et al., 2016; Tebrich, 2008; Doležal et al., 2017). The differences in VOCs composition of body odour from individuals were reported, with some common compounds present amongst the subjects and some compounds differed (Pandey \& Kim, 2011; Vera et al., 2019; Cuzuel et al., 2017; Curran et al., 2010; Jadoon et al., 2015). Although a similar compound was found in all subjects, the differences in terms of quantity of the compound were evident.

In foot odour, VOCs are absorbed into the surface of inner sole shoes and remained for several times. The previous study detected the presence of several C6-C10 straight chains, branched, and unsaturated acid from the analysis of shoe odour (Dormont et al., 2013). Another study reported the detection of acetic acid, propanoic acid, isobutyric acid, butyric acid, isovaleric acid, valeric acid, isocaproic acid, caproic acid and heptanoic acid that closely reproduced a full foot odour (Caroprese et al., 2009). A person that has a strong odour has a greater quantity of short-chain fatty acids, such as isovaleric acid that produced by metabolism of skin bacteria (Kanda et al., 1990).

The problem in understanding the origin of body odour is due to the complexity of the human skin secretion. The lack of standard operating guidelines and exposure of the law authorities to the science of this evidence is the main reason for the minimal application in the forensic field. Also, there is a limited understanding of the origin of odour associated with human body parts. To date, the variations of human odours precipitate after contact with personal belongings such as shoes and shirts have not been investigated for inclusion and exclusion of suspects. This study was aimed to gain a better understanding of the compositions of shoe odour and their characteristics for personal identification.

\section{Materials and methods Materials}

Materials used in this study were canvas shoes, $100 \%$ cotton swabs (EXCUE brands), silica gel 60 (Merck \& Co.), elastic-plastic purchased from the local supermarket. Acetone, n-hexane, methanol, isopropyl alcohol, and dodecanoic acid standard were purchased from Sigma Aldrich, UK.

\section{Operating conditions for GC-FID}

Method for VOCs analysis from the previous study on body odour analysis was referred and further optimised to improve the detection of the compounds (Pickett, 2017). Gas chromatography (GC) coupled with flame ionisation detector (FID) was utilised to analyse the shoe odour. The GC was equipped with G4513A Series Autosampler (Agilent Technologies) and Agilent J \& W $19091 \mathrm{~J}-413 \mathrm{HP}-5$ fused-silica capillary column $(30 \mathrm{~m} \times$ $0.25 \mu \mathrm{m} \times 0.320 \mathrm{~mm}$ ) with nitrogen as the carrier gas (flow rate, $1.0 \mathrm{~mL} / \mathrm{min}$ ). The inlet temperature was set at $300{ }^{\circ} \mathrm{C}$. The initial oven temperature was held for $2 \mathrm{~min}$ at $40^{\circ} \mathrm{C}$ then ramped at $25^{\circ} \mathrm{C} / \mathrm{min}$ until it reached $200{ }^{\circ} \mathrm{C}$ and held for $5 \mathrm{~min}$ and another $2 \mathrm{~min}$ for postrun. The detector was set up at $300^{\circ} \mathrm{C}$. The total run time was $12.5 \mathrm{~min}$. The Chemstation software (revision B.04.02) (Agilent Technologies, Santa Clara, CA) was used for data acquisition and processing. 


\section{Sampling methods}

Two sampling methods were tested, direct extraction with solvent and air passive sampling in order to determine the best sampling strategy for extraction of odour from the shoe. An old shoe was examined in this study, and the inner sole was divided into two areas for sampling using the respective methods.

\section{Direct extraction with a solvent method}

The inner sole of the old shoe was directly swabbed for 10 min with a cotton bud that was initially soaked in $70 \%$ isopropyl alcohol. The solvent employed for the extraction was a mixture of $70 \%$ acetone and $30 \% \mathrm{n}$ hexane. The cotton bud was cut and deposited into a clear glass vial and dissolved in $2 \mathrm{~mL}$ mixture of acetone- $n$-hexane solvent solution. The negative controls of neat swabs with each solvent were also analysed. The extracted sample was left for $10 \mathrm{~min}$ to maximise the extraction of VOC compounds. Five hundred microliters of the liquid sample was pipetted into a $2 \mathrm{~mL}$ GC vial, and $1 \mu \mathrm{l}$ of the sample was injected into the GC for analysis. Other solvent mixtures, namely acetone, n-hexane and methanol, were also tested in order to determine the suitable solvents to be used for extraction (Rajan, 2015).

\section{Air passive sampling method}

Two hundred milligrams of silica gel powder was weighed and placed inside the old shoes. The shoe was wrapped and sealed tightly with an elastic-plastic and heated inside the hot air oven (Fig. 1) to avoid the evaporation of VOCs to surroundings during the heating process. The oven was set to $60^{\circ} \mathrm{C}$, and the shoes were left inside the oven for $1 \mathrm{~h}$. After $1 \mathrm{~h}$, the shoe was taken out, and plastic was removed to collect the silica gel powder. The silica gel was then deposited into a clean glass vial and spiked with $1.5 \mathrm{~mL}$ of acetone. The vial was shaken vigorously for $5 \mathrm{~min}$, and the extracted sample was filtered into a GC vial using a $0.45 \mu \mathrm{m}$ PTFE syringe filter attached to a $5 \mathrm{~mL}$ syringe filter to remove the small particle powder. The negative control of wrapped neat new shoe that contained silica gel was also analysed. The extracted solution was then analysed using GC-FID. A similar method was also applied by using other solvents such as methanol and hexane (Pickett, 2017).

\section{Recovery}

The recovery study was conducted as part of the extraction process to determine the effectiveness of the extraction method. A new shoe was analysed for the purpose of the recovery study. Extraction was carried out using passive air sampling. A neat blank shoe contained 200 mg silica gel powder was spiked with $25 \mathrm{mg} / \mathrm{mL}$ of the dodecanoic acid in the insole area and wrapped tightly with an elastic-plastic wrapper. Dodecanoic acid is a volatile compound that presents on human skin. The shoe was heated at $60^{\circ} \mathrm{C}$ for $1 \mathrm{~h}$. Silica gel powder was then extracted with $1.5 \mathrm{~mL}$ of a suitable solvent, i.e. methanol, and pipetted to a GC vial using a PTFE syringe filter attached to a $5 \mathrm{~mL}$ syringe filter. The extract was analysed using GC-FID with the analytical parameters previously established. The spiked sample was analysed in triplicate, and the concentration of the spiked sample was calculated from the calibration curve. The calibration curve was constructed using five concentration levels $(1 \mathrm{mg} / \mathrm{mL}$ to $20 \mathrm{mg} / \mathrm{mL})$ of dodecanoic acid

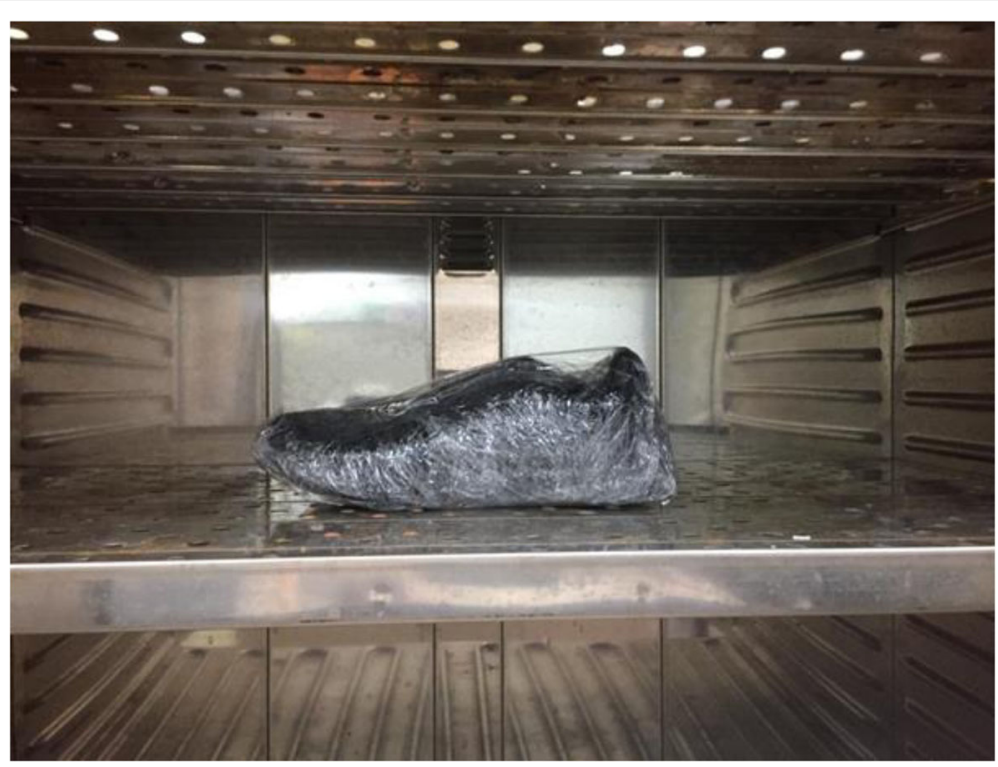

Fig. 1 Air passive sampling method of shoe odour sample 
standard solutions. The limit of detection (LOD) was estimated using the standard determination method, LOD: $3 S_{\mathrm{a}} / b ; S_{\mathrm{a}}$ is the standard deviation of the response while $b$ is the slope of the calibration curve.

\section{Analysis of real shoe odour samples}

Ten volunteers (five adult males and five adult females aged $31.1 \pm 8.7$ ) were provided with two pairs of new canvas shoes, which were classified as pair 1 and pair 2 and labelled with initials of the subjects (example, MA1 \& MB2). In order to conduct the study, human ethical approval was obtained from The Human Research Ethics Committee (JEPeM) Universiti Sains Malaysia (USM) Kubang Kerian, Kelantan (USM/JEPeM/19030200).

The test was conducted for 2 weeks. Subjects were asked to wear pair 1 for a week. Subjects were also instructed to wear the shoes during strenuous activities such as jogging, playing football or brisk walking for $2 \mathrm{~h}$ per day to maximise the production of sweat and increase the concentration of odour trapped in the shoe. The subjects were not allowed to wear socks or any lotion, cream, or anything onto the feet before and during the activities. During the 1 week of the experimental period, the shoes were stored inside a zipper storage plastic bag at room temperature every time the subjects completed their activities.

After 1 week of sample collection, the second pairs were given to the subjects while the first pairs were collected for sample extraction. Subjects needed to wear pair 2 for following 1 week and performing the same strenuous activities. Negative control (neat new shoe), as well as the two pairs of worn new shoes from each subject, was extracted using a passive air sampling method as described earlier, and the extract then analysed using GC-FID.

In total, there were 13 sets of the odour sample profiles to be subjected as the dataset for statistical analysis. Subjects A, B, C, D and E are males, and subjects F, G, $\mathrm{H}, \mathrm{I}$, and $\mathrm{J}$ are females. Three pairs of old shoes were collected from subjects A, B, and F as blind samples. These shoes were labelled as old shoes 1, 2 and 3, respectively, and extracted and analysed using the same procedure. The results of the blind samples were assessed to determine the consistency and accuracy of the predictive model in chemometrics analysis.

\section{Statistical analysis}

Principal Component Analysis-Discriminant Analysis (PCA-DA) was conducted to analyse the dataset utilising selected peaks in the chromatogram. PCA is a multivariate statistical method that enables the reduction of the dimensionality, which reconstructs the original dataset by creating a linear combination of variables. Upon the data transformation, the PCA software creates a new independent variable known as a principal component, which contains much of the original data set. A score plot for the first two or three principal components is often used to visualise the differences between samples that can be represented either in two-dimensional (2D) or three-dimensional (3D).

The score plot provides a more objective way of comparing variations between samples by showing the clustering of the sample. The closer the distance between a sample and forms a cluster on a score plot, the more similar they are according to the selected principal component. The first two components account or the largest possible variance in the data set. Discriminant analysis (DA) is a way to build a predictive model of group membership, which can then be applied to new cases or observations.

Prior to PCA, data of the selected peak undergone a pre-treatment procedure or pre-processing by normalisation of peak area to the total area of the selected peaks in each chromatogram (Ringnér, 2008). The analysis was conducted using the Minitab software v.16 (Minitab Incorporated, State College, USA).

\section{Results and discussion}

Preliminary analysis was conducted using a direct extraction method, where the extraction process was attempted using four different solvents. Based on the collected chromatograms, it was observed that the extraction of the swab sample was more effective using methanol and acetone as opposed to other solvents (Fig. 2). Extraction with methanol and acetone solvent resulted in a good resolution and separation of peaks in the chromatogram.

Air passive sampling was also tested for extraction, which involved the application of silica as sorbent material and heat exposure to determine the efficiency for detecting the real shoe odour samples. It was observed that the methanol extracted shoe odour sample again produced well-resolved peaks in the chromatogram when compared to acetone (Fig. 3). Several compounds of interest originated from shoe odour were evident as they were not present in the chromatogram of the negative control. Essentially, the air passive sampling method was noted to be reproducible as compared to direct extraction. The method was applied based on the adsorption concept of sorbent material with the VOCs odour from the shoes and the interaction with the solvent solution. VOCs are generally present in the vapour phase at room temperature $\left(0.0133 \mathrm{kPa}\right.$ at $\left.25^{\circ} \mathrm{C}\right)$. When the shoes were heated at $60^{\circ} \mathrm{C}$, the VOCs odour inside the shoes vaporised and released into a surrounding and adsorbed by the silica gel. Silica gel is one of the good adsorbent materials. Silica gel is considered as microporous sorbent 


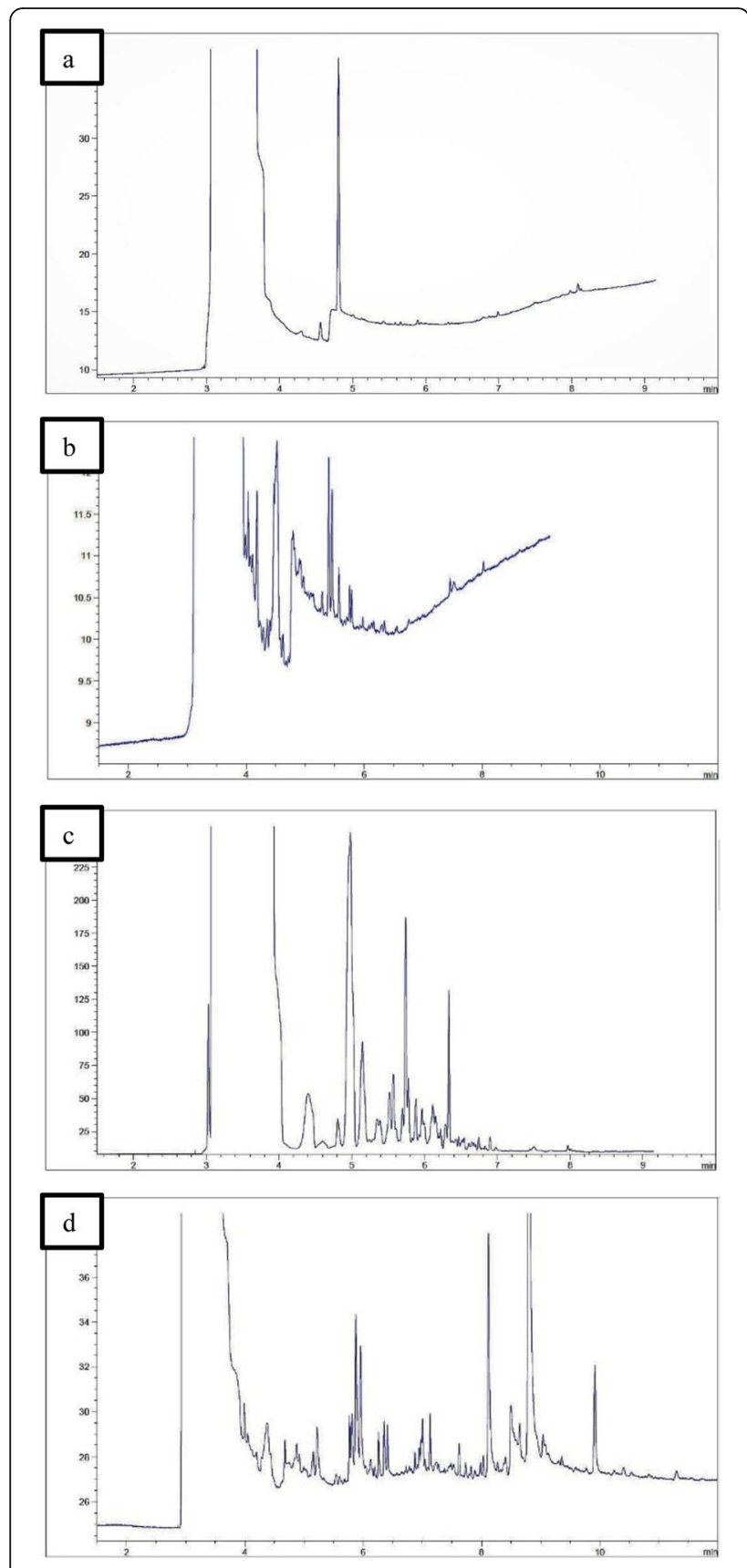

Fig. 2 Chromatogram of shoe odour samples collected by direct solvent extraction methods using four different types of solvents; (a) mixture acetone: $\mathrm{n}$-hexane, (b) n-hexane, (c) acetone and (d) methanol

as it has a small diameter size compared with other types of sorbent material (Harper, 2000).

This pore size had influenced the adsorption mechanism as it caused the adsorbed molecule packed closely and held by a strong force. After some period, the VOCs were desorbed from a solid sorbent with a liquid solvent for analytical analysis. It is crucial to utilise a suitable solvent that will not interfere with the detection of the analyte. Methanol is a suitable solvent to interact with a silica gel as this solvent is highly capable of desorbing the VOCs from the sorbent material, and it does not interfere with the analyte. According to Kennedy et al., the efficiency of the volatile to stripping the analyte from the solid sorbent is more than 75\% (Kennedy et al., 1994).

The recovery test is essential in order to estimate either the sample preparation was appropriate or not. Shabir had stated that the criteria for the recovery test of the method approximately $80 \%$ to $120 \%$ (Shabir, 2005). It was demonstrated that the percent recovery of the spiked dodecanoic acid standard using a passive air sampling method followed by extraction using methanol was above $95 \%$. This indicates that the air passive sampling method used for the sample pretreatment prior to GC-FID analysis was effective for the recovery of VOCs in shoe odour. The LOD of dodecanoic acid was calculated at $3.3 \mathrm{mg} / \mathrm{mL}$.

Figure 4 demonstrates the stacked chromatograms of the extracted odour from the shoe samples from subjects A, B and C. It was evident that the chromatograms between samples show variable patterns with reference to the peaks. Some similar peaks were observed in all samples. This supports the previous study on body odour that reported every person might have the same type of odour compound, but different in terms of quantity (Jadoon et al., 2015). Several additional peaks were also detected in the chromatograms. These peaks were unique, and characteristics to a person and can be used to differentiate this individual from others. The presence of the additional peaks in the analysis may be due to the additional condition of the subjects such as medicine or supplement intake, diet, and metabolism of the subject body. This was also demonstrated by a study conducted by Mebazaa et al., who found an additional compound in the GC analysis after the consumption of fenugreek (Mebazaa et al., 2011).

Surprisingly, dodecanoic acid did not present in any samples as there was no peak indicating dodecanoic acid in the chromatogram. The recovery obtained in the blank sample with a spike may not be the same as real samples since the analyte for both samples may not be integrated in the same manner (Van Reuuwijk, 1998). Theoretically, dodecanoic acid is a volatile compound that presents on human skin, as reported by the previous research (Vera et al., 2019). This condition might be due to the lower amounts of dodecanoic acid in real odour samples that were detected by the GC-FID. These results also postulated that dodecanoic acid is contained abundantly in human body odour or upper body areas and but not in the lower regions of the body, i.e. foot. Dodecanoic acid or lauric acid is one type of saturated fatty acids, similar to isovaleric. The previous study reported 

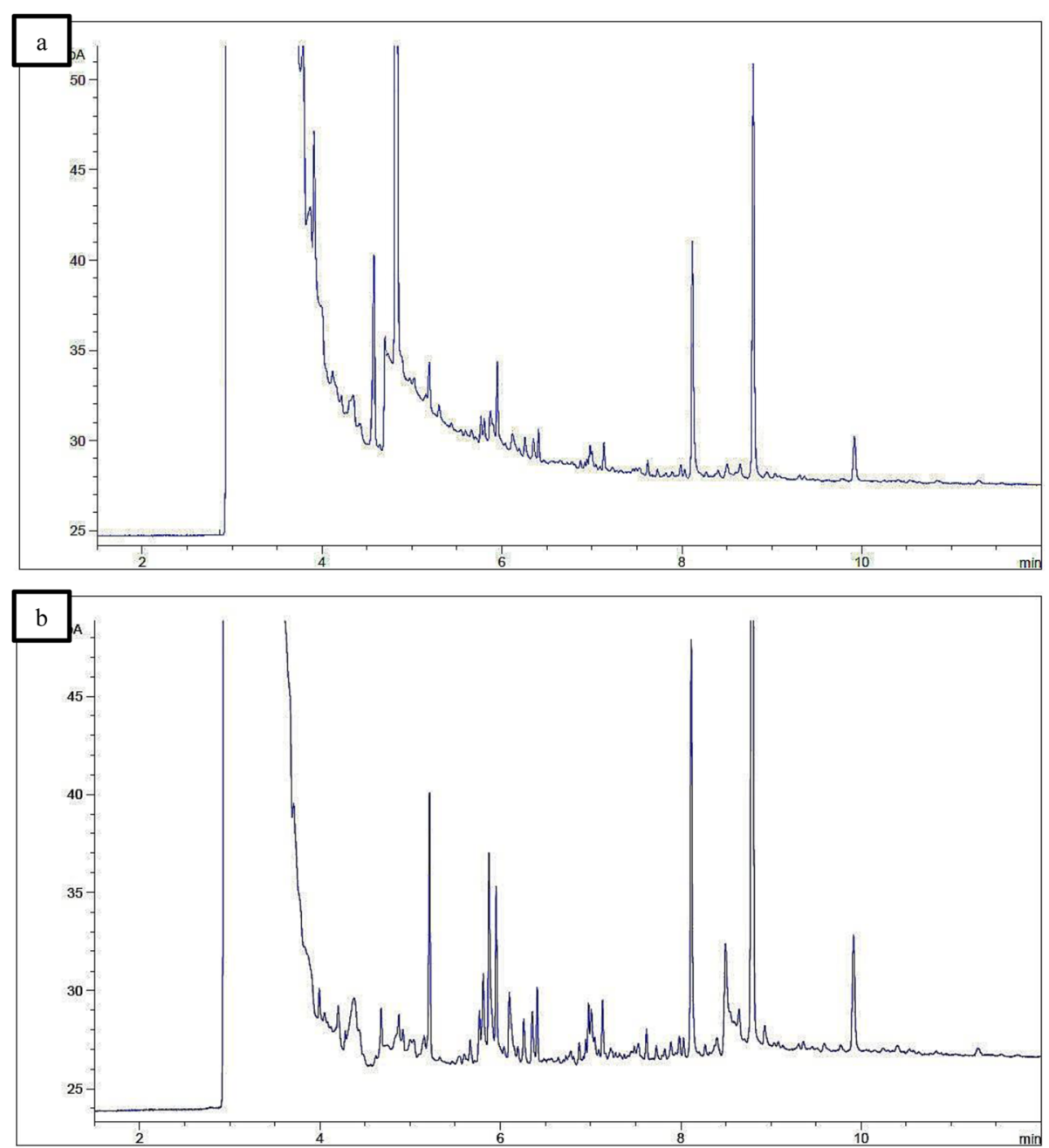

Fig. 3 Chromatogram of shoe odour samples collected by air passive sampling method using (a) acetone solvent and (b) methanol solvent

that dodecanoic acid is a part of a primary odour, which is found on the hand and arm of the subject (Pojmanová et al., 2019). The upper body, especially in the axillae part, consists of the apocrine gland that is responsible for most body odour compared with other glands. An odour produced from this gland tends to produce more volatile fatty acid as compared to the eccrine gland that associated with foot odour (Wedekind, 2007). Since this study was aimed only to profile VOCs odour from shoes only, further studies can be conducted using a GC-MS to identify the detected compound based on the mass spectral library or database.

Analysis of the patterns of GC profile to differentiate between individuals was still not sufficient as the visual examination was difficult, and subjective and subtle differences cannot be clearly seen. A multivariate analysis was carried out to measure the correlation between dataset, thus discriminating between shoe odour samples. PCA relies on a transformation set of original data into a smaller set of uncorrelated variables while remained the information of the original data (Olkin \& Sampson, 2001). A correlation set of data extracted from each chromatogram was chosen by selecting peaks at similar retention times in every chromatogram. Six retention times; 3.93, 4.5, 5.183, 8.47, 9.425 and 10.02 min were chosen as these peaks were detected and present in each chromatogram of the real shoe odour samples (Fig. 5).

Figure 6 illustrates the distribution of data point or score plot for shoe odour samples with a total of ten clusters labelled as A to J were observed. Principal components one and two account for $40.8 \%$ and $29.2 \%$, respectively, of the total variance in the data (cumulatively $70 \%$ ). Based on the score plot, it was noted that all samples were clustered separately and can be completely distinguished from one another. The score plots also reveal that odour samples from shoes of the same individual were grouped closely to form a distinct cluster. In other words, both pairs of shoes (shoes 1 and shoes 2) worn 


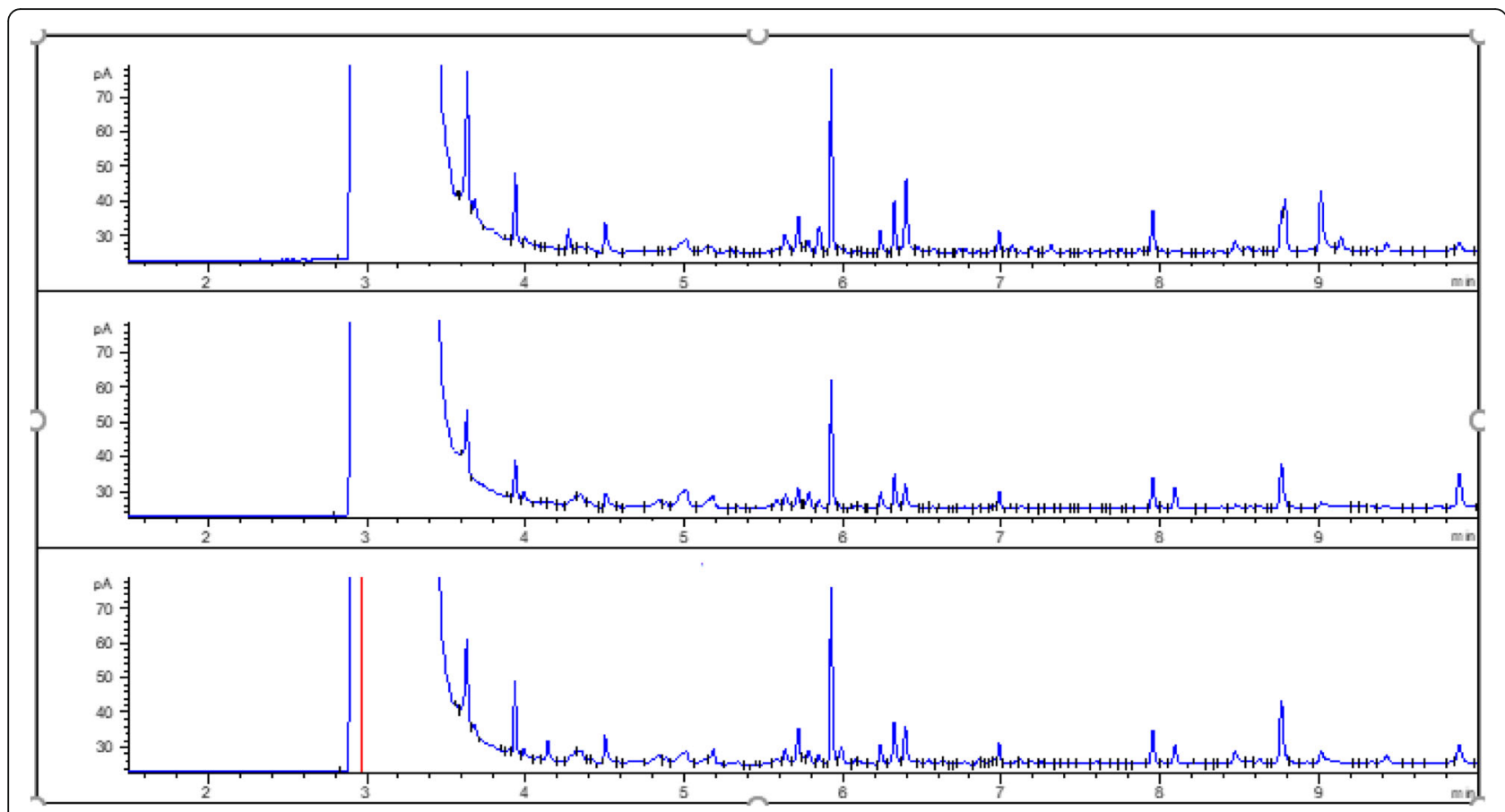

Fig. 4 Stacked chromatogram of shoes odour samples from three subjects

by a particular subject were grouped together and closed to each other. This result indicated that the odour samples from the same subject were reproducible, as presented by PCA and their chromatogram. However, it was noted that shoe odour samples from subjects $C$ and
G were clustered at a close distance as compared to those from other subjects.

The results of three blind samples remarkably showed that the odours originated from these old shoes were clustered in similar groups as worn new shoes belonged

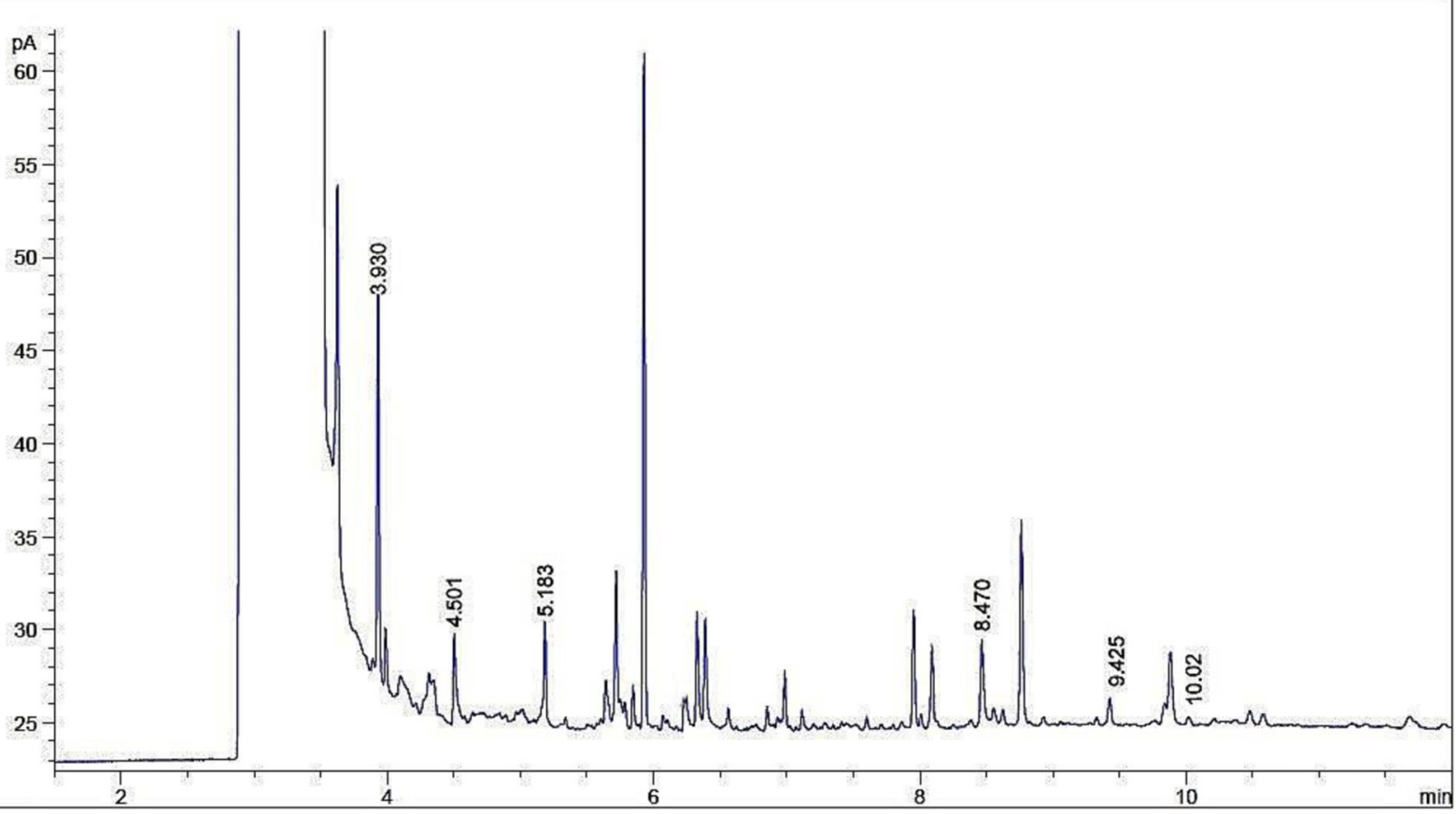

Fig. 5 Six chromatogram peaks chosen for PCA 


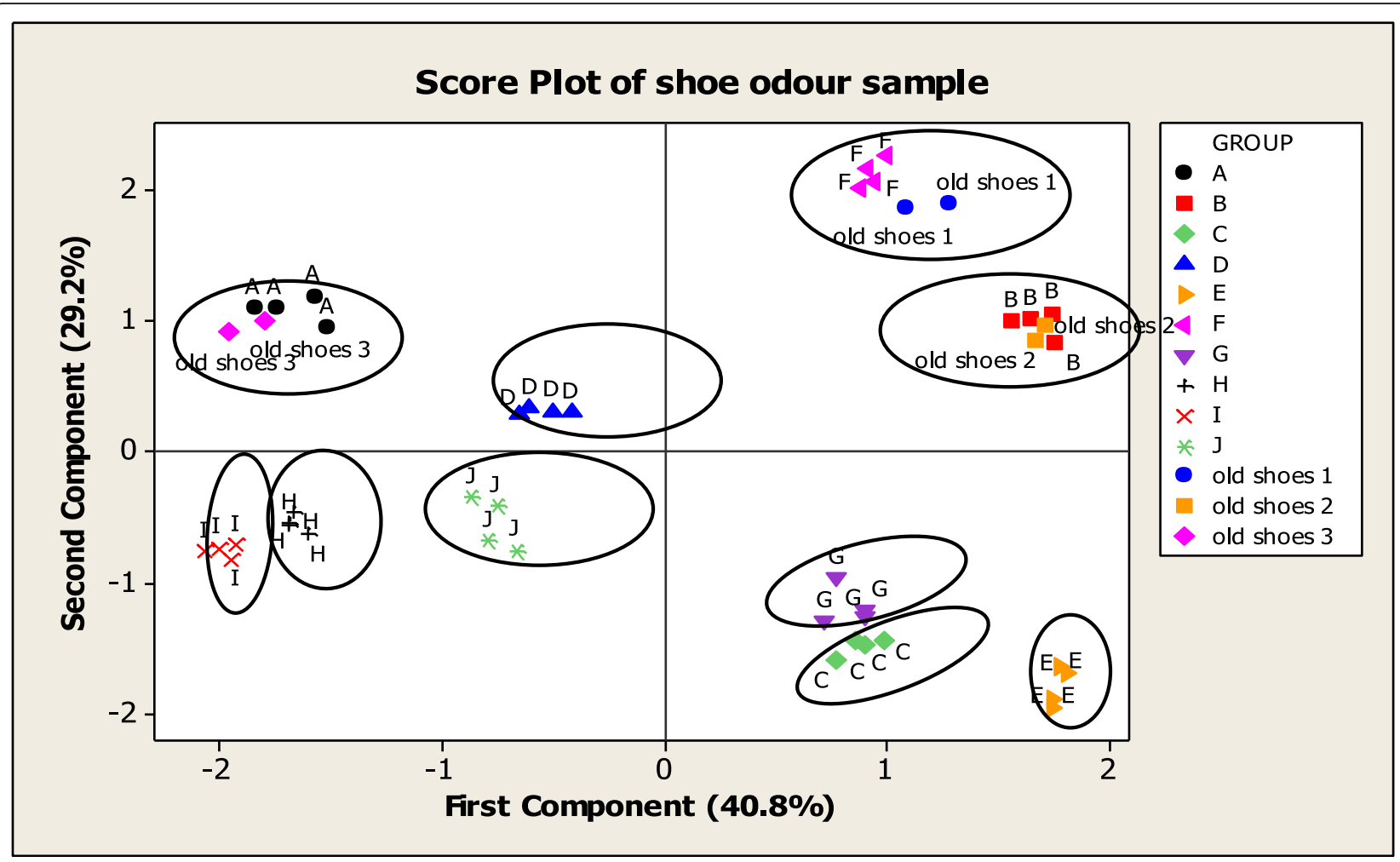

Fig. 6 Score plot of PC1 and PC2 for shoe odour samples

to the same owners. Odour samples from old shoes of subjects A and B were adjacent to those of from new worn shoes of the same subjects, while for old shoe samples of subject $F$, although still grouped together, the scores were noted slightly away from new shoe samples that were worn by the same subject. This may occur due to other interfering compounds originating from the shoes.

This study is in agreement with previous studies that reported that body odour could be employed to discriminate between individuals. The difference in the ratio of a combination compound that is forming an odour from one person to another proves that there is a highly significant variation of the body odour amongst the individual. This theory was also supported by a study on canine, which findings showed that canine was able to discriminate individuals, even identical twins, based on their odour (Vyplelová et al., 2014).

The composition of sweat consists of water, minerals and fatty acid in the body. A study conducted on metabolism effect of the body with a diet intake found that different diet produces a unique combination of fatty acid inside the body and combined with immune system response and carried to the sweat glands (Motil et al., 1981; Buttery et al., 1976). Analysis of diet diary collected from each subject during the experiment found that all the subjects had a different pattern of diet intake. Moreover, the intensity of the compounds was higher on some subjects as they consume some food that contains an ingredient that increases the production of unpleasant odour such as meat.

The overall results have proven that odour from shoes was unique and characteristic of the owner. However, the gender of individuals cannot be determined as samples from male and female subjects were scattered in the score plots and cannot be differentiated. The classification results of DA show that $100 \%$ of the samples were classified correctly to their groups, including all analysed old shoes as blind samples.

The limitations of this study should be noted for further exploration in future work. The small number of sample sizes/participants could not represent the total size of the population. In addition, uncontrolled exercise activities amongst participants would affect the collection of the sample as different subjects practised exercises with different intensities and cannot be quantified. Other confounding factors that may affect the variations of odour composition such as diet, smoking habit, disease conditions, or medical history of the participants were also not determined and shall be investigated in the future.

\section{Conclusion}

This research proves that human body odour is unique and different between persons, which can be used as 
individual fingerprint markers. The chromatogram patterns of the VOCs in shoe odour revealed variation between individuals. This was supported by the output of principal component analysis that demonstrated all samples were discriminated by forming distinct clusters according to the groups. The findings obtained from this study are of paramount importance in a forensic investigation as any evidence is a mute witness, and when properly analysed for instance, in this case, the shoe odour, the culprit can be arrested and punished by the Court of Law.

\section{Abbreviations}

C: Carbon chain; DA: Discriminant analysis; GC: Gas chromatography; GCFID: Gas chromatography-flame ionisation detector; GC-MS: Gas chromatography-mass spectrometry; LOD: Limit of detection; PCA: Principal component analysis; PTFE: Polytetrafluoroethylene; VOCs: Volatile organic compounds

\section{Acknowledgements}

Not applicable

\section{Authors' contributions}

All authors contributed to the design of the study. Muhammad Hafizuddin performed the experiments. All authors analysed the data, discussed and wrote the manuscript. The authors read and approved the final manuscript.

\section{Authors' information}

Not applicable

\section{Funding}

Financial support for this research by MOHE FRGS grant (FRGS/1/2019/ STG04/USM/02/5)

\section{Availability of data and materials}

Please contact author for data requests.

\section{Ethics approval and consent to participate}

The human ethical clearance was approved by Human Research Ethics Committee, Universiti Sains Malaysia (reference number: USM/JEPeM/ 19030200).

\section{Consent for publication}

Consent to publish was obtained from each participant.

\section{Competing interests}

The authors declare that they have no competing interests.

\section{Author details}

${ }^{1}$ Forensic Science Programme, School of Health Sciences, Universiti Sains Malaysia, Kubang Kerian, Kelantan, Malaysia. ${ }^{2}$ Biomedicine Programme, School of Health Sciences, Universiti Sains Malaysia, Kubang Kerian, Kelantan, Malaysia. ${ }^{3}$ Department of Basic Medical Sciences, Kuliyyah of Nursing, International Islamic University of Malaysia, Jalan Sultan Ahmad Shah, Bandar Indera Mahkota, Kuantan, Pahang, Malaysia.

Received: 4 November 2019 Accepted: 3 June 2020

Published online: 12 June 2020

\section{References}

Ara K, Hama M, Akiba S, Koike K, Okisaka K, Hagura T, Kamiya T, Tomita F (2006) Foot odor due to microbial metabolism and its control. Canadian J Microb 52:357-364

Brown JS, Prada PA, Curran AM, Furton KG (2013) Applicability of emanating volatile organic compounds from various forensic specimens for individual differentiation. For Sc Int 226:173-182
Buttery RG, Guadagni DG, Ling LC, Seifert RM, Lipton W (1976) Additional volatile components of cabbage, broccoli, and cauliflower. J Agricultural and Food Chem 24:829-832

Caroprese A, Gabbanini S, Beltramini C, Lucchi E, Valgimigli L (2009) HS-SPME-GCMS analysis of body odor to test the efficacy of foot deodorant formulations. Skin Res and Tech 15:503-510

Curran AM, Furton KG (2005) Analysis of the uniqueness and persistence of human scent. FBI 7

Curran AM, Prada PA, Furton KG (2010) The differentiation of the volatile organic signatures of individuals through SPME-GC/MS of characteristic human scent compounds. J For Sci 5:50-57

Curran AM, Rabin SI, Prada PA, Furton KG (2005) Comparison of the volatile organic compounds present in human odor using SPME-GC/MS. J Chem ECO 31:1607-1619

Curran AM, Ramirez CF, Schoon AA, Furton KG (2007) The frequency of occurrence and discriminatory power of compounds found in human scent across a population determined by SPME-GC/MS. J Chromatogr B 846:86-97

Cuzuel V, Cognon G, Rivals I, Sauleau C, Heulard F, Thiébaut D, Vial J (2017) Origin, analytical characterization and use of human odor in forensics. J For Sci 62:330-350

Doležal P, Kyjaková P, Valterová I, Urban Š (2017) Qualitative analyses of less-volatile organic molecules from female skin scents by comprehensive two dimensional gas chromatography-time of flight mass spectrometry. J Chrom A 1505:77-86

Dormont L, Bessière JM, Cohuet A (2013) Human skin volatiles: a review. J Chem Ecology 39:569-578

Gallagher M, Wysocki CJ, Leyden JJ, Spielman Al, Sun X, Preti G (2008) Analyses of volatile organic compounds from human skin. British J Derm 159:780-791

Gorea RK, Abhinav G, Arshdeep G (2016) Sweat analysis and its role in identification. Golbal J Nursing \& For Studies 1:1-3

Harper M (2000) Sorbent trapping of volatile organic compounds from air. J Chrom A 885:129-151

Havlicek J, Lenochova P (2008) Environmental effects on human body odour, in Hurst JL, Beynon, RJ, Roberts SC, Wyatt TD (Eds.), Chemical Signals in Vertebrates 11. Springer New York, pp. 199-210

Haze S, Gozu Y, Nakamura S, Kohno Y, Sawano K, Ohta H, Yamazaki K (2001) 2Nonenal newly found in human body odor tends to increase with aging. J Investigative dermatology 116:520-524

Hunt R (1999) The benefits of scent evidence. FBI L. Enforcement Bull. 68:15

Jacob S, McClintock MK, Zelano B, Ober C (2002) Paternally inherited HLA alleles are associated with women's choice of male odor. Nat Gen 30:175-179

Jadoon S, Karim S, Akram MR, Kalsoom KA, Zia MA, Siddiqi AR, Murtaza G (2015) Recent developments in sweat analysis and its applications. Int J Anal Chem 2015:1-7

Jeltema MA, Southwick EW (1986) Evaluation and applications of odor profiling. J Sensory Studies 1:123-136

Jha SK, Hayashi K (2017) Molecular structural discrimination of chemical compounds in body odor using their GC-MS chromatogram and clustering methods. Int J Mass Spec 423:1-14

Kalmus $H$ (1955) The discrimination by the nose of the dog of individual human odours and in particular of the odours of twins. The British J Ani Behaviour 3 : 25-31

Kanda F, Yagi E, Fukuda M, Nakajima K, Ohta T, Nakata O (1990) Elucidation of chemical compounds responsible for foot malodour. British J Derm 122:771-776

Kennedy ER, Fischbach TJ, Song R, Eller PM, Shulman SA (1994) Guidelines for air sampling and analytical method development and evaluation. National Inst. for Occupational Safety and Health, Cincinnati, $\mathrm{OH}$

Li S (2014) Recent developments in human odor detection technologies. J For Sci \& Crim 1:1-12

Marshall J, Holland KT, Gribbon EM (1988) A comparative study of the cutaneous microflora of normal feet with low and high levels of odour. J Appl. Bacteriol 65:61-68

Mebazaa R, Rega B, Camel V (2011) Analysis of human male armpit sweat after fenugreek ingestion: characterisation of odour active compounds by gas chromatography coupled to mass spectrometry and olfactometry. Food Chemistry 128:227-235

Motil KJ, Matthews DE, Bier DM, Burke JF, Munro HN, Young VR (1981) Wholebody leucine and lysine metabolism: response to dietary protein intake in young men. American J Physiology-Endo and Met 240:E712-E721

Olkin I, Sampson AR (2001) Multivariate analysis: overview. In: Smelser NJ, Baltes PB (eds) International Encyclopedia of the Social \& Behavioral Sciences. Pergamon, Oxford, pp 10240-102471 
Pandey SK, Kim KH (2011) Human body-odor components and their determination. TrAC Trends in Anal Chem 30:784-796

Pickett TE (2017) Correlating the perception of foot odour and the amount of odorous chemicals present in (textile chemistry). North Carolina State University, Raleigh, North Carolina

Pojmanová P, Ladislavová N, Škeříková V, Kania P, Urban Š (2019) Human scent samples for chemical analysis. Chemical Papers.

Rajan R (2015) Method development for forensic analysis of body odour using gas chromatography mass spectrometry. Universiti Sains Malaysia, Kubang Kerian Kelantan, MSc Thesis

Rajan R, Nik Hassan NF, Islam MN (2013) Chemical fingerprinting of human body odor: an overview of previous studies. Malaysian J For Sc 4:33-38

Rennie PJ, Gower DB, Holland KT (1991) In-vitro and in-vivo studies of human axillary odour and the cutaneous microflora. British J Derm 124:596-602

Ringnér M (2008) What is principal component analysis? Nat Biotechnol 26(3): 303-304

Sergeant MJ (2010) Female perception of male body odor, in: Vitamins \& Hormones. Elsevier, pp. 25-45

Shabir GA (2005) Step-by-step analytical methods validation and protocol in the quality system compliance industry. J Val Tech 10:314-325

Shirasu M, Touhara K (2011) The scent of disease: volatile organic compounds of the human body related to disease and disorder. J Biochem 150:257-266

Sorokowska A, Butovskaya M, Veselovskaya E (2015) Partner's body odor vs. relatives' body odor: a comparison of female associations. Polish Psychological Bulletin 46:209-213

Tebrich S (2008) Human scent and its detection. CIA Historical Review Program Van Reuuwijk LP (1998) Quality of analytical procedure, in: Guideline for Quality Management in Soil and Plant Laboratories. FAO and ISRIC

Vera F, Giulio Di M, Marcello R, Palmira F, Pietrantonio R, Cristoforo P, Giovanni M, Irene R, Christian Z, Antonietta M, Monica S and Francesco Sessa (2019) Volatile organic compounds: instrumental and canine detections link an individual to the crime scene. Egypt J For Sci 9:35

Vyplelová P, Vokálek V, Pinc L, Pacáková Z, Bartoš L, Santariová M, Čapková Z (2014) Individual human odor fallout as detected by trained canines. For Sci Int 234:13-15

Wallace P (1977) Individual discrimination of humans by odor. Physiology \& Behavior 19:577-579

Wedekind C (2007) Body odour and body odour preference in human, in: oxford handbook of evolutionary psychology. Oxford University Press, New York

\section{Publisher's Note}

Springer Nature remains neutral with regard to jurisdictional claims in published maps and institutional affiliations.

\section{Submit your manuscript to a SpringerOpen ${ }^{\circ}$ journal and benefit from:}

- Convenient online submission

- Rigorous peer review

- Open access: articles freely available online

- High visibility within the field

- Retaining the copyright to your article

Submit your next manuscript at $\boldsymbol{\nabla}$ springeropen.com 